THe lucigenin-dependent chemiluminescence generation by guinea-pig isolated tracheal two rings preparations was studied. Tracheal preparations stimulated with phorbol myristate acetate (PMA) or opsonized zymosan generated chemiluminescence. The total amount of chemiluminescence generated in $120 \mathrm{~m}$ in $w$ as $754 \pm 63 \mathrm{mV} \times \mathrm{m}$ in for PMA and $4832 \pm$ $396 \mathrm{mV} \times \mathrm{min}$ for zymosan. Generation of chemiluminescence was decreased by more than $50 \%$ when the tissues were co-incubated with superoxide dismutase $(100 \mathrm{U} / \mathrm{ml})$. Also, addition of direct donors of nitric oxide diminished chemiluminescence generation by zymosan-activated tracheal rings significantly by about $50 \%$. However, the presence of the precursor or of in hibitors of nitric oxide synthase did not influence zymosan-induced chemiluminescence. Removal of the epithelial layer from tracheal rings caused an approximately $90 \%$ decrease in chemiluminescence response. However, isolated epithelial cell suspensions did not generate chemiluminescence. Histologic examination showed that the number of eosinophils in the tracheal tissue was reduced from $56 \pm 7$ to $18 \pm 8$ per $\mathrm{mm}$ basal membrane when the epithelial layer was removed. These results indicated that (1) superoxide anion formation can take place in the guinea-pig trachea, (2) eosinophils in the epithelial and submucosal layers of guinea-pig trachea are likely candidates for superoxide generation although other cell types can also be involved, and (3) besides relaxing airway smooth muscle, nitric oxide donors may also affect superoxide in the airways.

Key words: Chemiluminescence, Airways, Eosinophils, Nitric oxide, Oxygen radicals

\section{Role of the epithelial layer in the generation of superoxide anion by the guinea-pig isolated trachea}

\author{
G. Sadeghi-Hashjin, ${ }^{1}$ P. A. J. Henricks, ${ }^{1, C A}$ \\ G. Folkerts, ${ }^{1}$ T. Muis, ${ }^{1}$ J. Garssen ${ }^{2}$ \\ and F. P. Nijkamp ${ }^{1}$
}

${ }^{1}$ Department of Pharmacology and Pathophysiology, Utrecht Institute for Pharmaceutical Sciences, Utrecht University, PO Box 80.082, 3508 TB Utrecht; ${ }^{2}$ Department of Immunobiology and Hematology, National Institute for Public Health and the Environment, PO Box 1, 3720 BA Bilthoven, The Netherlands

\author{
${ }^{\mathrm{CA}}$ Corresponding Author \\ Tel: $(+31) 302537358$ \\ Fax: (+31) 302537420 \\ Email: p.a.j.henricks@far.ruu.nl
}

\section{Introduction}

The respiratory burst is a characteristic response of granulocytes and macrophages when exposed to soluble or particulate stimuli. ${ }^{1}$ Reactive oxygen species formed during this process, are essential for killing microorganisms but play also an important role in tissue damage as frequently observed in inflammation or reperfusion injury. ${ }^{2}$ Superoxide anion is an important oxygen species generated by several metabolic processes including xanthine oxidase, NADPH oxidase, P450 monooxygenase and several other enzymatic systems. ${ }^{3-6}$ Radical production by cells is characterized by the emission of chemiluminescence. ${ }^{7-9}$ Chemiluminescence amplifiers such as luminol or lucigenin, are used to increase the sensitivity to detect oxygenation activity and superoxide production of cells. ${ }^{9,10}$ Luminol reacts with hydrogen peroxide or singlet oxygen, the secondary reaction products of superoxide, and is peroxidase-dependent, whereas lucigenin- enhanced chemiluminescence is specific for superoxide.

In the respiratory system, radicals, including superoxide and nitric oxide, are produced by inflammatory cells. ${ }^{11}$ Nitric oxide is released by several cell types, including epithelial cells, in the lung and airways, and recognized as a mediator of multiple physiologic processes. ${ }^{12,13}$ Nitric oxide is also probably involved in the pathogenesis of airway hyperresponsiveness. ${ }^{14,15}$ The rapid reaction between superoxide and nitric oxide leads to the production of peroxynitrite. ${ }^{16}$ Peroxynitrite is able to cause tissue injury ${ }^{17}$ and to induce airway hyperresponsiveness. ${ }^{18}$ Radicals are usually short-lived molecules and could be more harmful for cells in the airway tissue if released from adherent cells rather than from cells in the airway lumen. In this study, we investigated the production of superoxide by cells of the airway tissue. This was measured by the generation of lucigenin-enhanced chemiluminescence from intact tracheal rings with special atten- 
tion to the interaction with nitric oxide and the role of the epithelial layer.

\section{Materials and Methods}

\section{Animals and tissue preparation}

Specified pathogen-free guinea-pigs (400-500 g, male Dunkin Hartley, Harlan Olac Ltd, UK) were housed under controlled conditions. Water and commercial chow were allowed ad libitum. The guinea-pigs were free of respiratory infections as assessed by the health monitoring quality control report by Harlan Porcellus (UK), and by histological examination. Guinea-pigs were killed with an overdose of pentobarbital sodium (Nembutal, $0.6 \mathrm{~g} / \mathrm{kg}$ body weight, intraperitoneal). Tracheas were dissected free of connective tissue and blood vessels, isolated, and segmented into parts of two rings each. In some experiments, the epithelial layer was removed by means of cotton swab without morphological damage to the underlying tissue. ${ }^{15}$

\section{Isolation of guinea-pig tracheal epithelial cells}

Guinea-pig trachea was isolated and dissected free of connective tissue, filled with sterile MEM containing $1 \mathrm{mg} / \mathrm{ml}$ protease $\mathrm{E}$ (pronase). Trachea then was suspended in $20 \mathrm{ml}$ sterile MEM and kept at $4^{\circ} \mathrm{C}$ for $18 \mathrm{~h}$. Thereafter, inside of trachea was rinsed with $10 \mathrm{ml}$ MEM containing 10\% FCS thoroughly and cells were recovered. The suspension was centrifuged at $240 \times g$ for $10 \mathrm{~min}$. The supernatant was discarded and the pellet was resuspended in MEM 10\%FCS. The centrifugation step was repeated and the pellet was resuspended in $1 \mathrm{ml}$ Krebs buffer. Cells were stained with Türk solution and counted in a Bürker-Türk counting chamber. For differentiation, cells were spun on microscope slides at $45 \times \boldsymbol{g}$ for $5 \mathrm{~min}$, fixed and stained with Dade ${ }^{\circledR}$ Diff-Quik $^{\circledR}$ (Baxter Diagnostics AG, Düdingen, Switzerland). Differential counts were made under oil immersion microscopy. About $7 \times 10^{6}$ cells were isolated from one trachea and the isolated cell populations contained $87 \%$ epithelial cells and 13\% eosinophils whereas other cell types were not present.

\section{Lucigenin-dependent chemiluminescence}

Generation of chemiluminescence was measured with a LKB-1251 Luminometer (LKB Wallac, Turku, Finland). Tracheal two ring preparations were placed in luminometer cuvettes containing lucigenin $(50 \mu \mathrm{l})$, zymosan A $(100 \mu \mathrm{l})$ or phorbol myristate acetate (PMA; $50 \mu \mathrm{l}$ ), in a final volume of $0.5 \mathrm{ml} \mathrm{Krebs} \mathrm{buffer.}$ Lucigenin, a chemiluminescence indicator ${ }^{8}$, was used at a final concentration of $500 \mu \mathrm{M}$. Opsonized zymosan and PMA were used as cellular stimulants at final concentrations of $2.5 \mathrm{mg} / \mathrm{ml}$ and $0.16 \mu \mathrm{M}$, respec- tively, in the reaction mixture. Zymosan A had been opsonized for $15 \mathrm{~min}$ at $37^{\circ} \mathrm{C}$ with $100 \%$ pooled guinea-pig serum. After opsonization, zymosan was centrifuged at $1600 \times g$ for $15 \mathrm{~min}$ and resuspended in buffer. When the effects of $100 \mathrm{U} / \mathrm{ml} \mathrm{SOD}, 400 \mu \mathrm{M}$ L-arginine (the precursor for the synthesis of nitric oxide), $100 \mu \mathrm{M} \mathrm{L-N}{ }^{G}$-nitro-arginine (L-NNA; an inhibitor of nitric oxide synthesis), $100 \mu \mathrm{M}$ histamine, $1 \mu \mathrm{M}$ sodium nitroprusside (SNP) or $1 \mu \mathrm{M} S$-nitroso$\mathrm{N}$-acetylpenicillamine (SNAP; direct donors of nitric oxide) were studied on the generation of chemiluminescence of the tracheal preparations, $50 \mu \mathrm{l}$ of a 10 -fold concentrated solution of each compound was used in place of an equal volume of Krebs buffer. Che miluminescence was measured every 5 min over a $120 \mathrm{~min}$ time period at $37^{\circ} \mathrm{C}$. In some experiments (incubation with histamine), chemiluminescence was determined every $10 \mathrm{~s}$ over a $10 \mathrm{~min}$ period. The integrated response was determined with a computer program supplied with the luminometer. Data are presented as peak chemiluminescence production $(\mathrm{mV})$ as well as the area under curve (AUC) over $120 \mathrm{~min}(\mathrm{mV} \times \mathrm{min})$ or $10 \mathrm{~min}(\mathrm{mV} \times \mathrm{s})$. Chemiluminescence generation by isolated guinea-pig epithelial cell preparations $\left(5 \times 10^{5}\right.$ cells $)$ was determined upon stimulation with PMA or opsonized zymosan and measured every min over a 60 min time period at $37^{\circ} \mathrm{C}$.

\section{Histology}

Control and epithelium-denuded tracheas were fixed for at least $24 \mathrm{~h}$ in phosphate-buffered formaldehyde (10\%). Thereafter, they were dehydrated and embedded in paraplast (Monoject, Kildare, Ireland). Four $\mu \mathrm{m}$ thick sections were stained with Giemsa and evaluated by light microscopy. For quantitative histopathologic analysis of the trachea, length of the basement membrane and number of eosinophils per mm length were measured using a computerized interactive analysis system (IBAS 2000; Kontron, Munich, Germany). Eosinophils in and/or just under the epithelium were counted.

\section{Drugs and solutions}

MEM and FCS were purchased from Gibco (Grand Island, UK), SNAP from Alexis Corporation (Läafelfingen, Switzerland) and Protease E (Pronase), PMA, histamine diphosphate, lucigenin, Zymosan A, SOD, L-arginine, and L-NNA from Sigma (St Louis, MO). PMA was dissolved in DMSO $(1 \mathrm{mg} / \mathrm{ml})$ and the stock solution was kept at $-80^{\circ} \mathrm{C}$. Stock solutions of 5 mMlucigenin in the buffer were stored at $-20^{\circ} \mathrm{C}$. The Krebs-bicarbonate buffer was of the following composition (mM/L): $\mathrm{NaCl}, 118.1 ; \mathrm{KCl}, 4.7 ; \mathrm{CaCl}_{2}, 2.5$; $\mathrm{MgSO}_{4}, 1.2 ; \mathrm{NaHCO}_{3}, 25.0 ; \mathrm{KH}_{2} \mathrm{PO}_{4}, 1.2$ and glucose, 8.3. 


\section{Statistical analysis}

The peak $(\mathrm{mV})$ or AUC $(\mathrm{mV} \times \min )$ of generated chemiluminescence by individual treatment groups were averaged and expressed as means \pm SEM. The results of each set of experiments were evaluated by one-way analysis of variance (ANOVA). If significance was achieved by one-way analysis, post-ANOVA comparison of means was performed using Bonferroni tests. All $P$-values $<0.05$ were considered to reflect a statistically significant difference.

\section{Results}

Chemiluminescence generation by tracheal two ring preparations

No generation of chemiluminescence by tracheal rings was detectable under basal (non-stimulated) conditions. In contrast, PMA- and zymosan-treated tracheal preparations generated chemiluminescence (Fig. 1). Zymosan induced more chemiluminescence by tracheal preparations when compared with PMA (PMA: $754 \pm 63 \mathrm{mV} \times$ min, zymosan: $4832 \pm 396 \mathrm{mV}$ $X$ min, mean total chemiluminescence generated in 120 min (AUC) \pm SEM, $n=5$ ). Treatment with SOD diminished the effects of PMA and zymosan; total chemiluminescence generated was significantly declined by more than 50\% (Fig. 1; PMA + SOD: 367 $\pm 24 \mathrm{mV} \times \mathrm{min}$, zymosan + SOD: $2179 \pm 184 \mathrm{mV} \times$ min, mean \pm SEM, $n=5 ; P<0.05$ when compared with stimulation without SOD).

\section{Role of the epithelial layer in generation of} chemiluminescence

Removal of the epithelial layer resulted in a marked decrease of chemiluminescence generation by the

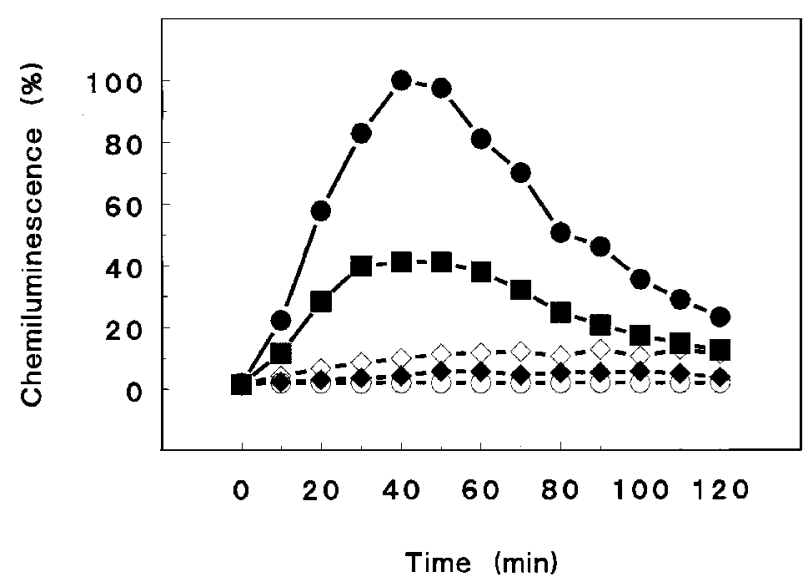

FIG. 1. Generation of chemiluminescence by isolated guineapig two ring tracheal preparations without stimulation (O), after stimulation with zymosan $(\bullet)$ or PMA $(\diamond)$ and after stimulation with zymosan ( $\square$ ) and PMA $(\bullet)$ in the presence of SOD.

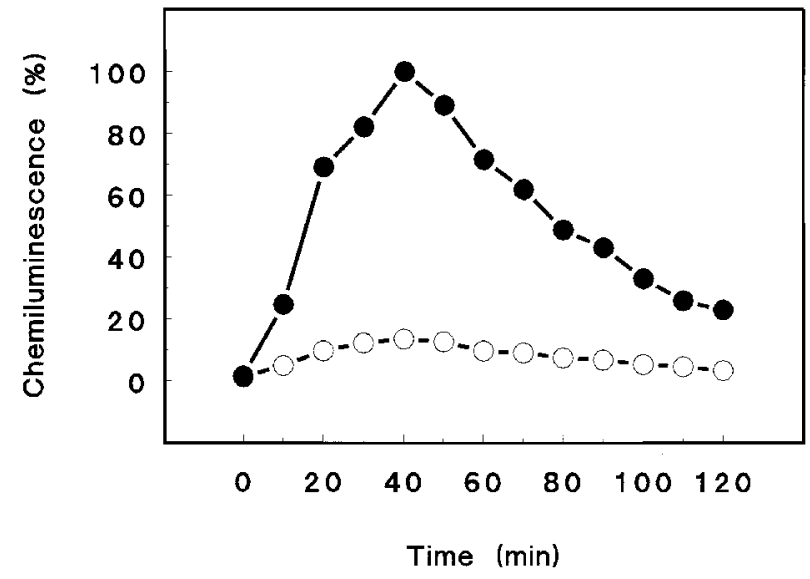

FIG. 2. Zymosan-induced chemiluminescence generation by isolated guinea-pig two ring tracheal preparations with $(\mathbf{O})$ or without epithelial layers $(\bigcirc)$.

zymosan-stimulated tracheal rings (Fig. 2; intact: peak $81 \pm 21 \mathrm{mV}$ and total chemiluminescence $4942 \pm$ $1397 \mathrm{mV} \times$ min, epithelial layer removed: peak $13 \pm$ $6 \mathrm{mV}$ and total chemiluminescence $519 \pm 99 \mathrm{mV} \times$ min, $n=16, P<0.05)$.

Cell populations isolated from the internal lining of trachea (87\% epithelial cells and 13\% eosinophils) generated low amounts of chemiluminescence. Peak chemiluminescence generated by $5 \times 10^{5}$ cells of these isolated cell populations after stimulation with zymosan was $4 \pm 2 \mathrm{mV}$ and total chemiluminescence in $60 \mathrm{~min}$ was $209 \pm 74 \mathrm{mV} \times$ min.

\section{Histology}

In the control tracheas, intact pseudo-stratified columnar epithelium with its lamina propria and a submucosal layer were observed by microscopic examination of the preparations. Eosinophils were abundant in the mucosal and submucosal layers (56.1 \pm 7.2 eosinophils per $\mathrm{mm}$ basal membrane). These layers were completely absent in the epitheliumdenuded preparations without any visual damage to the smooth muscle. In this group the number of eosinophils per mm basal membrane was declined to $18.0 \pm 8.2(n=6 ; P<0.05)$.

Interaction of nitric oxide and superoxide in the trachea

SNP $(1 \mu \mathrm{M})$ significantly inhibited the peak and total chemiluminescence generation evoked by zymosanactivated trachea by $50 \%$ (Fig. 3A; zymosan: peak $47 \pm$ $8 \mathrm{mV}$ and total chemiluminescence $2965 \pm 475 \mathrm{mV} \times$ min, zymosan + SNP: peak $21 \pm 4 \mathrm{mV}$ and total chemiluminescence $1669 \pm 192 \mathrm{mV} \times \min , n=14, P$ $<0.05)$. Other compounds beside NO are released during the decomposition of SNP which may affect 


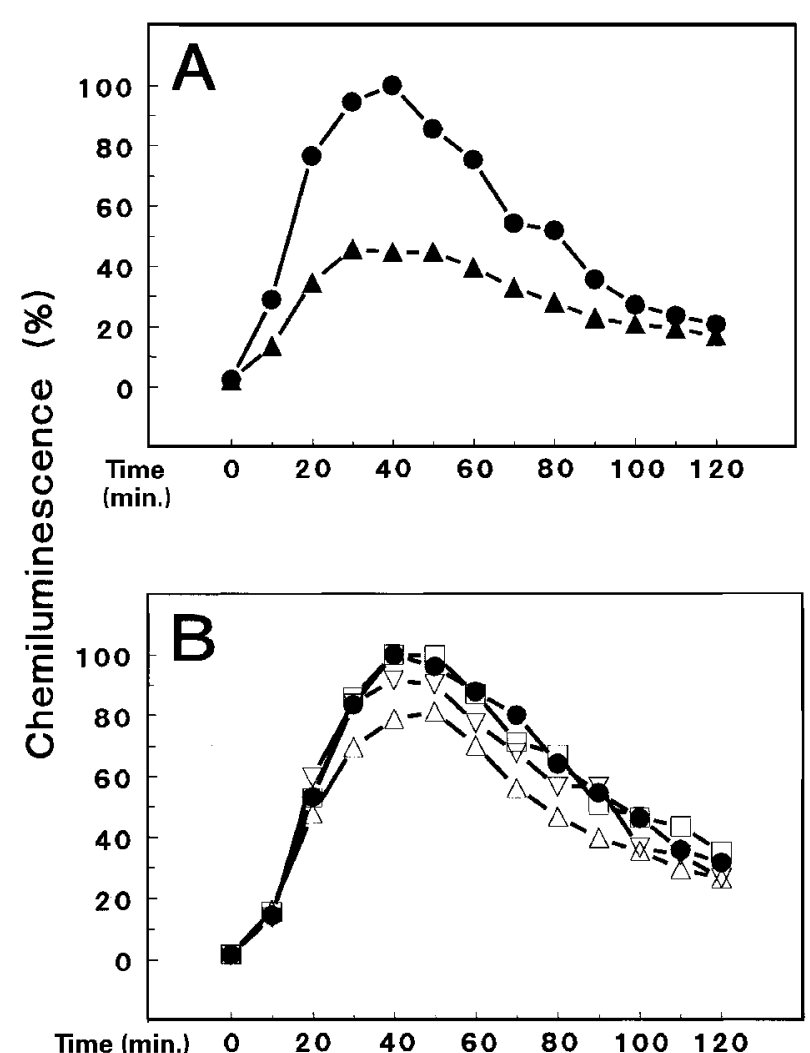

FIG. 3. Interaction between nitric oxide and superoxide released from tracheal preparations. $(\boldsymbol{A})$. Zymosan-induced chemiluminescence generation by isolated guinea-pig two ring tracheal preparations in the absence $(\mathbf{0})$ or presence of sodium nitroprusside (A). (B). Zymosan-induced chemiluminescence generation in the presence of $100 \mu \mathrm{M}$ histamine by isolated guinea-pig two ring tracheal preparations in the absence $(\bullet)$ or presence of L-arginine $(\triangle), L-N^{G}$-nitroarginine $(\nabla)$ or a combination of L-arginine and L-N $\mathrm{N}^{G}$-nitroarginine $(\square)$.

the chemiluminescence response. Therefore, experiments were also carried out with SNAP as another nitric oxide-donor. SNAP was also able to diminish chemiluminescence generation by zymosan-stimulated tracheal preparations (zymosan: peak $52 \pm 6 \mathrm{mV}$ and total chemiluminescence $2794 \pm 112 \mathrm{mV} \times \mathrm{min}$, zymosan $+1 \mu \mathrm{M}$ SNAP: peak $28 \pm 3 \mathrm{mV}$ and total chemiluminescence $1703 \pm 201 \mathrm{mV} \times \min , n=3, P<$ 0.05).

To investigate the role of endogenous nitric oxide, the tracheal rings were treated with histamine which activates constitutive nitric oxide synthase. ${ }^{14}$ In these experiments, chemiluminescence was measured every $10 \mathrm{~s}$ over a 10 -min period. Addition of histamine $(100 \mu \mathrm{M})$ by itself did not cause any chemiluminescence generation by tracheal tissue (control: $928 \pm$ $49 \mathrm{mV} \times \mathrm{s}$, histamine: $866 \pm 64 \mathrm{mV} \times \mathrm{s}$, mean total chemiluminescence generation in $10 \mathrm{~min} \pm \mathrm{SEM}, n=$ $3)$. There were no differences between the amounts of chemiluminescence generated by tracheal rings treated with zymosan and histamine (control group) and preparations treated with Larginine, L-NNA, or a combination of both (Fig. 3B).

\section{Discussion}

The guinea-pig isolated trachea produced superoxide anion upon stimulation with particulate and soluble stimuli as measured by the generation of lucigeninenhanced chemiluminescence. The phenomenon was dependent on the presence of the epithelial layer. However, it was probably not the epithelial cells themselves but other cell types within the epithelial and submucosal layers that participated in generation of chemiluminescence. Endogenous production of nitric oxide in the trachea did not influence chemiluminescence measurements whereas addition of exogenous nitric oxide via nitric oxide donors inhibited the generation of chemiluminescence.

Reactive oxygen species are produced by activated phagocytes and damage mammalian cells. ${ }^{19}$ Superoxide anion, an oxygen-centred radical is an oxidation-reduction reagent, capable of either oxidation to molecular oxygen or reduction to hydrogen peroxide with the liberation of large amounts of energy. ${ }^{20}$ Spontaneous production of this radical has been show $n$ at sites of antigen challenge in allergic subjects and it contributes to the pathogenesis of airway injury associated with allergic inflammation. ${ }^{21}$ We have shown that airway hyperresponsiveness is induced when the guinea-pig isolated trachea is subjected to pyrogallol, a superoxide-generating substance. ${ }^{22}$ Hydrogen peroxide, another reactive oxygen species, damages ciliated epithelial cells and induces hyperresponsiveness of human isolated peripheral airways. ${ }^{23}$ Our study demonstrated that superoxide is formed by the cells resident in the airway epithelial and submucosal layers upon incubation with PMA or zymosan. PMA has been found to induce large and consistent effects on superoxide production by human neutrophils ${ }^{24}$ and opsonized zymosan is widely used to stimulate phagocytic response and oxygen radical release. ${ }^{25}$ The peak and total production of chemiluminescence by tracheal rings was considerably higher with zymosan than with PMA, suggesting the importance of the phagocytotic process in the formation of reactive species. The generation of chemiluminescence was inhibited by SOD confirming that superoxide is involved in lucigeninenhanced chemiluminescence generation.

Removal of the epithelial layer resulted in a substantial decrease in the generation of chemiluminescence by zymosan-activated tracheal tissue. This observation suggests that cells in the epithelial and/or submucosal layers play a crucial role in the production of oxygen species in guinea-pig trachea. It has been shown by others that cultured tracheal epithelial cells from guinea-pigs are able to release hydrogen peroxide. ${ }^{26}$ However, the epithelial cells themselves are probably not responsible for the chemiluminescence measured in our experiments since the amount of oxygen radicals produced by 
epithelial cells is very $\operatorname{low}^{26}$ and isolated epithelial cells did not react in response to zymosan. Alveolar macrophages, which are present deep in the lungs, were also not involved in chemiluminescence generation in the trachea as they were not present among the cells isolated from the epithelial lining of the tissue. However, a considerable number of eosinophils reside in the epithelial layer which might have been responsible for the radical release as these kind of cells are potent superoxide generators. ${ }^{27}$

Administration of L-arginine or L-NNA did not influence generation of chemiluminescence by zymosan-and histamine-stimulated guinea-pig trachea. This experiment was performed in the presence of histamine because it has been shown that histamine releases nitric oxide from guinea-pig tracheal epithelium. ${ }^{14}$ The amount of nitric oxide generated by the tracheal tissue was probably too low to interfere with the generation of chemiluminescence. The tracheal tissues were obtained from healthy animals where probably only the constitutive nitric oxide synthe tase was present. Others have shown that the chemiluminescence generation by rat macrophages is potentiated by the nitric oxide precursor L-arginine and inhibited by L-NNA. ${ }^{11}$ However, in that study luminol was used as the chemiluminescence amplifying agent ${ }^{11}$ but it has been shown that arginineanalogous non-specifically affects luminol-dependent chemiluminescence responses ${ }^{28}$.

To find out whether superoxide formation can be affected by nitric oxide, experiments were carried out with nitric oxide donors, like SNP and SNAP. Interestingly, addition of SNP or SNAP caused a significant decrease in chemiluminescence generation. It is known that nitric oxide can interact rapidly with superoxide to produce the more cytotoxic substance peroxynitrite. ${ }^{29}$ This substance has been shown to be produced in vivo in acute lung injury in humans ${ }^{17}$ and to induce airway hyperresponsiveness in guinea-pigs. ${ }^{18}$ The formation of peroxynitrite could explain the mechanism by which SNP or SNAP decreased chemiluminescence because less superoxide is than available to be measured by the lucigenin-dependent chemiluminescence measurement. Alternatively, nitric oxide and superoxide may influence each other also at other biological levels. ${ }^{30,31}$ Our finding is consistent with a recent report that SNP and nitric oxide inhibited fMLP-induced superoxide formation in human polymorphonuclear leukocytes. $^{32}$

Measurement of radical release in the isolated, intact tracheal rings from guinea-pigs is a new approach to study the role of oxygen radicals in the pathogenesis of airway disease. Using this method, cells are not affected by isolation procedures and resemble more the natural situation in response to stimuli compared with isolated cells. In addition, within the tracheal tissue the cell-cell interaction is preserved and provides another advantage to this sort of investigation over isolated cells. The present study suggested that (1) superoxide anion formation can take place in the guinea-pig trachea, (2) eosinophils in the epithelial and submucosal layers of guinea-pig trachea are likely candidates for superoxide production although the involvement of other cell types cannot be ruled out, and (3) besides relaxing airway smooth muscle, SNP and SNAP may also affect superoxide in the airways.

\section{References}

1. Baggiolini M, Wymann MP. Turning on the respiratory burst. Trends Biochem Sci 1990; 15: 69-72.

2. Sies H, Flohe L, Zimmer G. Molecular Aspects of Inflammation. Berlin: Springer-Verlag, 1991.

3. Babior BM. Oxygen-dependent microbial killing by phagocytes. New Engl J Med 1978; 298: 659-688.

4. Fridovich I. Superoxide radical: an endogenous toxicant. Annu Rev Pharmacol Toxicol 1983; 23: 239-257.

5. Kuthan $\mathrm{H}$, Ulrich V. Oxidase and oxygenase function of the microsomal cytochrome P450 monooxygenase system. Eur J Biochem 1982; 126: 583-588.

6. Mc Cord JM, Fridovich I. The reduction of cytochrome $c$ by milk xanthine oxidase. J Biol Chem 1968; 243: 5753-5760.

7. Allen RC, Stjernholm RL, Steele RH Evidence for the generation of an electronic excitation state(s) in human polymorphonuclear leukocytes and its participation in bacterial activity. Biochem Biophys Res Commun 1972; 47: 679-684.

8. Campbell AK. Chemiluminescence Principles and Applications in Biology and Medicine. Chichester: Ellis Horwood, 1988.

9. Stevens P, Hong D. The role of myeloperoxidase and superoxide anion in the luminol- and lucigenin-dependent chemiluminescence of human neutrophils. Microchem J 1984; 30: 135-146.

10. Faulkner K, Fridovich I. Luminol and lucigenin as detectors for $\mathrm{O}_{2}$ - Free Radical Biol Med 1993; 15: 447-451.

11. Wang J-F, Komarov P, De Groot H. Luminol chemiluminescence in rat macrophages and granulocytes: the role of $\mathrm{NO}, \mathrm{O}_{2} / / \mathrm{H}_{2} \mathrm{O}_{2}$, and $\mathrm{HOCl}$ Arch Biochem Biophys 1993; 304: 189-196.

12. Jorens PG, Vermeire PA Herman AG. Larginine-dependent nitric oxide synthase: a new metabolic pathway in the lung and airways. Eur Respir J 1993; 6: 258-266.

13. Nijkamp FP, Folkerts G. Nitric oxide and bronchial reactivity. Clin Exp Allergy 1994; 24: 905-914.

14. Folkerts G, Van der Linde HJ, Nijkamp FP. Virus-induced airway hyperresponsiveness in guinea pigs is related to a deficiency in nitric oxide. J Clin Invest 1995; 95: 26-30.

15. Nijkamp FP, Van der Linde HJ, Folkerts G. Nitric oxide synthesis inhibitors induce airway hyperresponsiveness in the guinea pig in vivo and in vitro; role of the epithelium. Am Rev Respir Dis 1993; 148: 727-734.

16. Saran M Reaction of $\mathrm{NO}$ with $\mathrm{O}_{2}$. Implications for the action of endothelium-derived relaxing factor (EDRF). Free Radical Res Commun 1990; 10: 221-226.

17. Kooy NW, Royall JA, Ye YZ, Kelly DR, Beckman JS. Evidence for in vivo peroxynitrite production in human acute lung injury. Am J Respir Crit Care Med 1995; 151: 1250-1254.

18. Sadeghi-Hashjin G, Folkerts G, Henricks PAJ, Verheyen AKCP, van der Linde HJ, van Ark I, Coene A, Nijkamp FP. 1996. Peroxynitrite induces airway hyperresponsiveness in guinea pigs in vitro and in vivo. Am J Respir Crit Care Med 1996; 153: 1697-1701.

19. Ward PA. Mechanisms of endothelial cell injury. J Lab Clin Med 1991; 118: 421-425.

20. Yamazaki I, Piette LH The mechanism of aerobic oxidase reaction catalyzed by peroxidase. Biochim Biophys Acta 1963; 77: 47-64.

21. Sanders SP, Zweier JL, Harrison SJ, Trush MA, Rembish SJ, Liu MC. Spontaneous oxygen radical production at sites of antigen challenge in allergic subjects. Am J Respir Crit Care Med 1995; 151: 1725-1733.

22. Sadeghi-Hashijn G, Folkerts G, Henricks PAJ, Van de Loo PGF, Van der Linde HI, Dik IEM, Nijkamp FP. Induction of guinea pig airway hyperresponsiveness by inactivation of guanylate cyclase. Eur J Pharmacol 1996; 302: 109-115.

23. Hulsmann AR, Raatgeep HR, Den Hollander JC, Stijnen T, Saxena PR, Kerrebijn KF De Jongste JC. Oxidative epithelial damage produces hyperresponsiveness of human periferal airways. Am J Respir Crit Care Med 1994; 149: 519-525.

24. Lehrer RI. Phorbol diesters and the production of superoxide by human neutrophils. Adv Inflammation Res 1992; 4: 181-195. 
25. Heberer M, Ernst M, Drig M. Measurement of chemiluminescence in freshly drawn human blood. Clinical application of zymosan-induced chemiluminescence. Klin Wochenschr 1982; 60: 1443-1448.

26. Kinnula VL, Adler KB, Ackley NJ, Crapo JD. Release of reactive oxygen species by guinea pig tracheal epithelial cells in vitro. Am JPhysiol 1992; 262: L708-L712.

27. Woschnagg C, Rak S, Venge P. Oxygen radical production by blood eosinophils is reduced during birch pollen season in allergic patients. Clin Exp Allergy 1996; 26: 1064-1072.

28. Dikshit M, Chari SS, Seth P, Kumari R. Interaction of nitric oxide synthethase inhibitors and Denantiomers with rat neutrophil luminol dependent chemiluminescence response. Br J Pharmacol 1996; 119: $578-582$.

29. Radi R, Cosgrove TP, Beckman JS, Freeman BA. Peroxynitrite-induced luminol chemiluminescence. Biochem J 1993; 290: 51-57.

30. Rengasamy A, Johns RA. Inhibition of nitric oxide synthase by a superoxide generating system. J Pharmacol Exp Ther 1993; 267: 1024-1027.
31. Wink DA, Hanbauer I, Krishna MC, DeGraaf W, Gamson J, Mitchell JB. Nitric oxide protects against cellular damage and cytotoxicity from reactive oxygen species. Proc Natl Acad Sci USA 1993; 90: 9813-9817.

32. Morikawa M, Inoue M, Tokumaru S, Kogo H Enhancing and inhibitory effects of nitric oxide generation in human polymorphonuclear leukocytes. Br J Pharmacol 1995; 115: 1302-1306.

ACKNOWLEDGEMENTS. The authors would like to thank Henk J. van der Linde and Marja C. van den Tweel for their technical assistance in the preparation of isolated tracheas and epithelial cells. G. S-H was financially supported by the Netherlands Asthma Foundation.

Received 16 October 1997; accepted in revised form 4 November 1997 


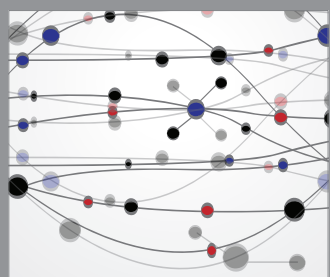

The Scientific World Journal
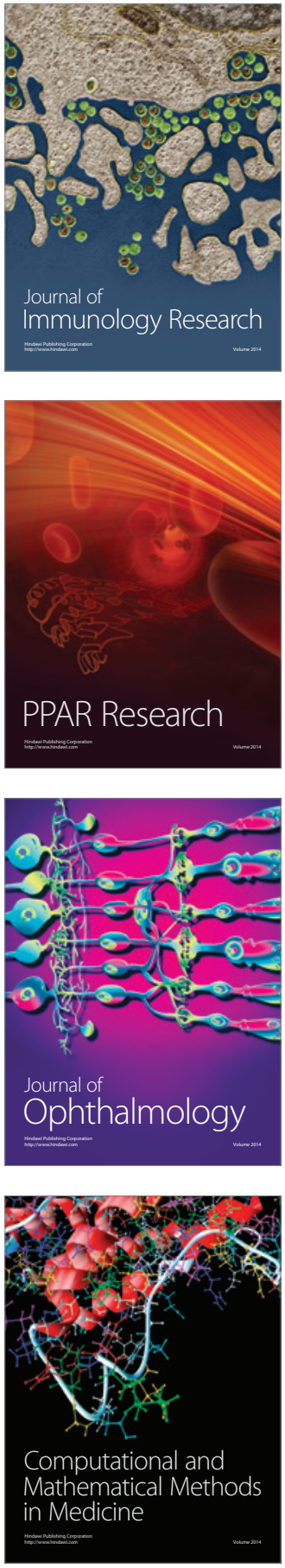

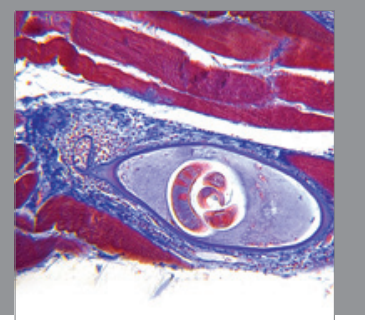

Gastroenterology

Research and Practice
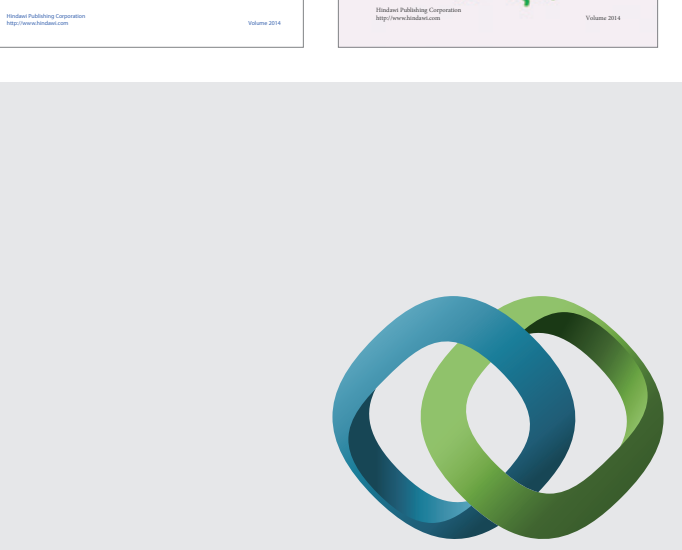

\section{Hindawi}

Submit your manuscripts at

http://www.hindawi.com
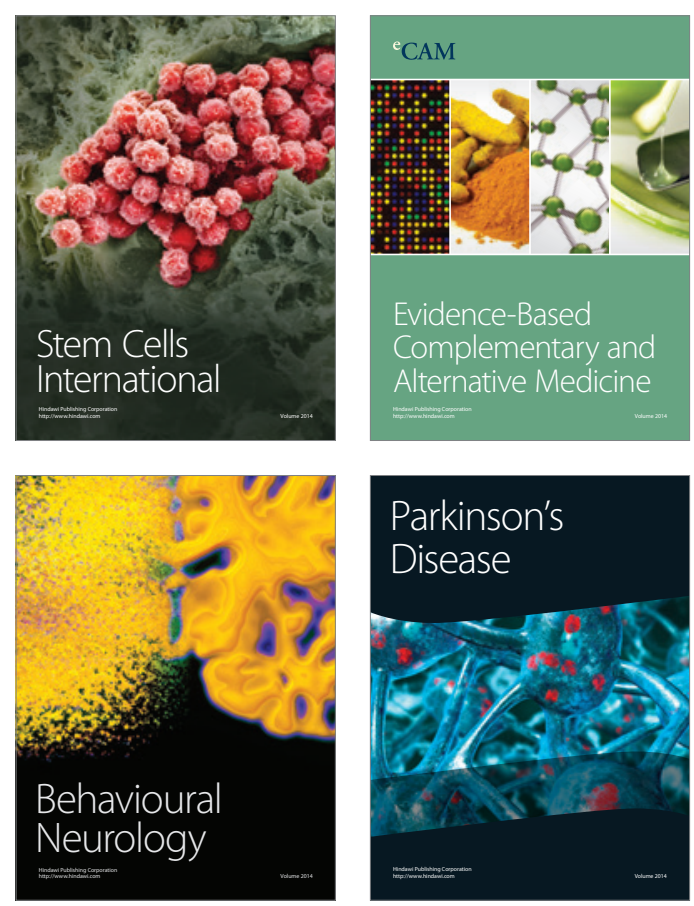

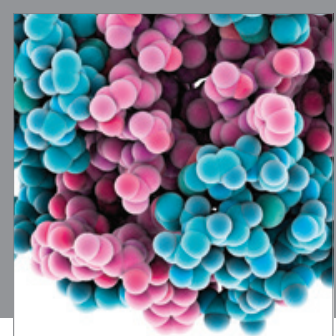

Journal of
Diabetes Research

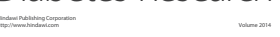

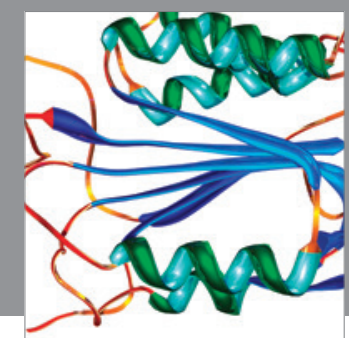

Disease Markers
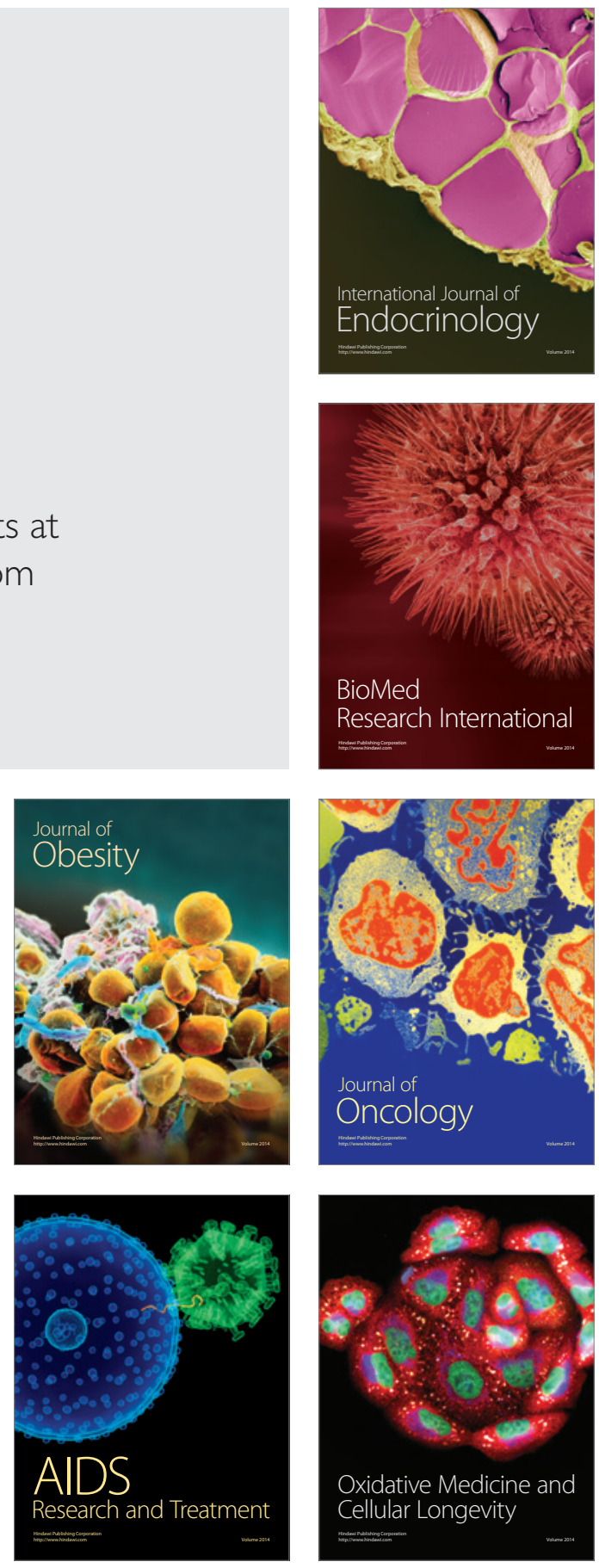